\title{
Clinical Trial Team Training Material
}

National Cancer Institute

\section{Source}

National Cancer Institute. Clinical Trial Team Training Material. NCI Thesaurus. Code C115606.

A collection of clinical trial-relevant team training resources. 